\title{
Liquid flow friction factor and heat transfer coefficient in small channels: an experimental investigation
}

\author{
Bruno Agostini ${ }^{\mathrm{a}, \mathrm{c}, *}$, Barbara Watel ${ }^{\mathrm{a}, \mathrm{b}}$, André Bontemps ${ }^{\mathrm{a}, \mathrm{b}}$, Bernard Thonon ${ }^{\mathrm{a}}$ \\ ${ }^{a}$ CEA-GRETh, 17 rue des Martyrs, 38054 Grenoble, France \\ ${ }^{\mathrm{b}}$ LEGI/GRETh, Université Joseph Fourier, 17 rue des Martyrs, 38054 Grenoble, France \\ ' ADEME, 2 Square Lafayette, 49004 Angers, France
}

\begin{abstract}
This article presents friction factor and heat transfer coefficient experimental results obtained with a liquid flow of R134a in rectangular mini-channels. Two test sections made of aluminium multi-port extruded (MPE) tubes (channels dimensions $1.11 \times 1.22$ $\mathrm{mm}$ and $0.73 \times 0.72 \mathrm{~mm}$ ) were tested. Mass flux ranges from 65 to $2900 \mathrm{~kg} / \mathrm{m}^{2} \mathrm{~s}$ and heat flux from 210 to $49700 \mathrm{~W} / \mathrm{m}^{2}$. The emphasis has been put on metrology problems and how they influence experimental results in mini-channels. Literature correlations for large tubes were found to predict our results reasonably well.
\end{abstract}

\section{Introduction}

New environmental policies for global warming prevention are based on a drastic reduction of greenhouse effect gases emissions. One solution is the miniaturization of heat exchangers thanks to mini-channels (hydraulic diameter about $1 \mathrm{~mm}$ ) whose increased heat transfer coefficients allow a reduced fluid inventory and a better thermal efficiency. They are already widely used in vehicles air conditioning condensers and are bound to be used in evaporators and domestic climatisation.

Results found in literature about heat transfer in mini-channels ([1-3]) for single-phase flow are often contradictory and operating conditions change from one study to another so that comparisons are difficult. Detailed information on geometry like tube roughness and hydraulic diameter uniformity or fluid distribution are often missing which could explain a discrepancy in results. Performances of mini-channels are under-estimated by classical correlations such as Chen [4], Shah [5] or Liu and Winterton [6] established for large diameter tubes. Thus a test loop has been set-up to study forced

${ }^{*}$ Corresponding author.

E-mail address: agostinibr@chartreuse.cea.fr (B. Agostini). convection heat transfer in MPE industrial mini-channels with R134a. This article presents single-phase flow results. The study of boiling heat transfer is in progress.

\section{Experiment description}

\subsection{The test loop}

Fig. 1 shows the test loop used for this study. It is made of two distinct circuits, the main circuit with the $\mathrm{R} 134 \mathrm{a}$ flow where the test section is inserted and a secondary cooling circuit with $0{ }^{\circ} \mathrm{C}$ glycol-water mixture to cool the fluid heated in the test section. The main elements of the R134a circuit are a centrifugal pump (Micropump, $220 \mathrm{~V}, 200 \mathrm{~W}, 10-100 \mathrm{l} / \mathrm{h}$ ), a counter flow heat exchanger (Vicarb 11 plates) for the R134a cooling, a liquid tank and a coriolis mass flowmeter (Rosemount Micromotion CMF 025, 0-1090 kg/h) with a 4-20 mA transmitter. Heat is extracted out of the glycol-water mixture thanks to a R22 cooling unit.

\subsection{The test section}

Fig. 2 shows the test section and its instrumentation. Both ends are equipped with $90^{\circ}$ manifolds for the fluid distribution. The tube diameter used for these manifolds is ten times the mini-channels hydraulic diameter in 


\section{Nomenclature}

\section{Latin letters}

$D_{\mathrm{h}} \quad$ hydraulic diameter, $\mathrm{m}$

$e \quad$ wall thickness, $\mathrm{m}$

$h \quad$ channel height, $\mathrm{m}$

$L \quad$ tube heated length, $m$

$L_{\text {th }} \quad$ thermal entry length, $m$

$l$ channel width, $\mathrm{m}$

$\dot{M}$ total mass flow rate, $\mathrm{kg} / \mathrm{s}$

$\dot{m} \quad$ mass flux, $\mathrm{kg} / \mathrm{m}^{2} \mathrm{~s}$

$p \quad$ pressure, bar

$\Delta p \quad$ pressure loss, bar

$\dot{q} \quad$ heat flux, $\mathrm{W} / \mathrm{m}^{2}$

$S \quad$ internal heated surface, $\mathrm{m}^{2}$

$T$ temperature, $\mathrm{K}$

$\Delta T_{\text {sub }} \quad$ sub sub-cooling, $\mathrm{K}$

$\Delta z \quad$ total tube length, $\mathrm{m}$

Greek letters

$\alpha \quad$ heat transfer coefficient $\mathrm{W} / \mathrm{m}^{2} \mathrm{~K}$

$\gamma=h / l$ aspect ratio

$\xi \quad$ singular pressure loss coefficient

$\lambda$ thermal conductivity, $\mathrm{W} / \mathrm{m} \mathrm{K}$

$\mu \quad$ dynamic viscosity, $\mathrm{Ns} / \mathrm{m}^{2}$
Subscripts

$\begin{array}{ll}\text { atm } & \text { atmosphere } \\ \text { bulk } & \text { bulk flow } \\ \text { exp } & \text { experimental } \\ \text { f } & \text { friction } \\ \text { fl } & \text { fluid } \\ \mathrm{G} & \text { global } \\ \mathrm{g} & \text { gravity } \\ \mathrm{i} & \text { inlet } \\ \text { o } & \text { outlet } \\ \text { sing } & \text { singular } \\ \text { w } & \text { wall }\end{array}$

Dimensionless numbers

$f \quad$ friction factor

$N \quad$ number of tubes

$\mathrm{Nu} \quad$ Nusselt number

$\operatorname{Pr} \quad$ Prandtl number

$R e=\dot{m} \cdot D_{\mathrm{h}} / \mu_{l}$ Reynolds number

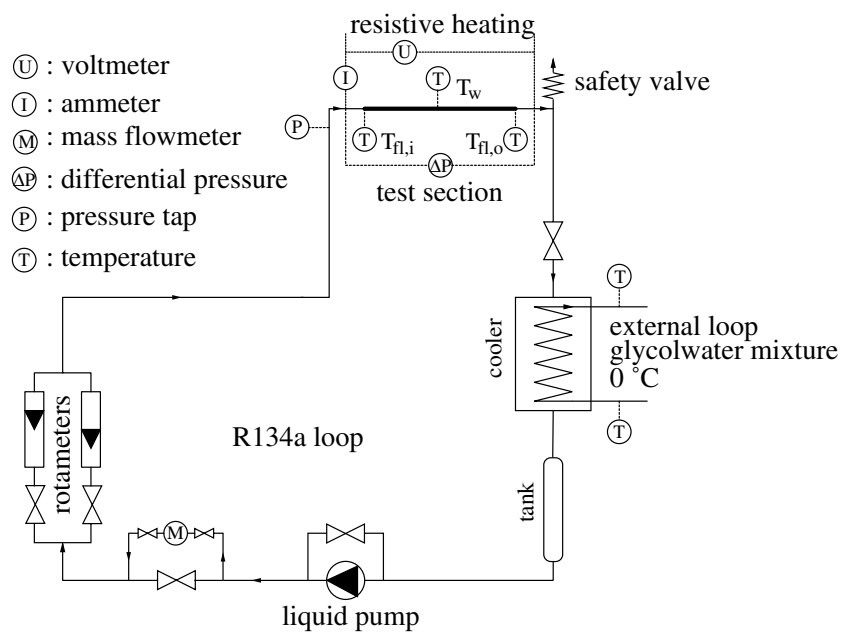

Fig. 1. The test loop.

order to suppress fluid distribution problems. The whole item was thermally insulated with foam. The test section itself is made of two functional parts: an adiabatic section for the flow hydrodynamic entry length, (ㅁ), and a heating zone placed between two pairs of electrodes brazed on the tube to perform a joule effect heating, (2). The electrodes are connected to a power supply (up to 2800 A) with two pairs of $240 \mathrm{~mm}^{2}$ cross-section copper cables. As the manufacturers' data on the channels geometry were not accurate enough for this study we
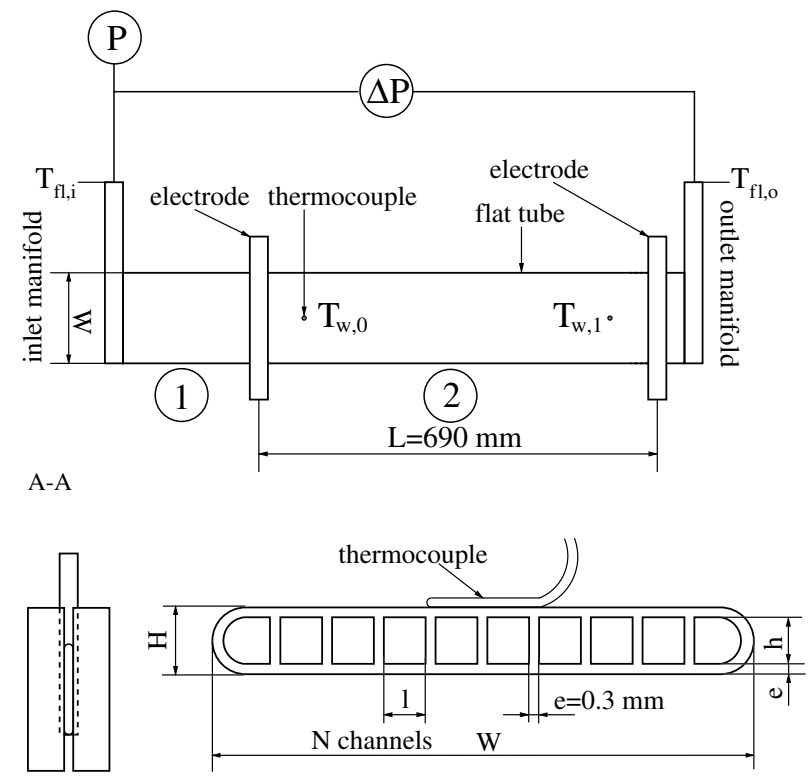

Fig. 2. The test section.

undertook our own dimensions measurements with an electron microscope after polishing in a resin matrix. Table 1 shows results averaged on several different channels. Uncertainties are twice the standard deviation ( $95 \%$ of data in this interval).

For wall temperature measurements two thermocouples (type E, $0.5 \mathrm{~mm}$ diameter, $0{ }^{\circ} \mathrm{C}$ reference) are 
Table 1

Hydraulic diameter measurements

\begin{tabular}{lllllll}
\hline Tube & $\bar{l}(\mathrm{~mm})$ & $\bar{h}(\mathrm{~mm})$ & $\bar{D}_{\mathrm{h}}(\mathrm{mm})$ & $\gamma$ & $N$ & $W(\mathrm{~mm})$ \\
\hline 1 & $1.11 \pm 0.02$ & $1.22 \pm 0.01$ & $1.17 \pm 0.05$ & $1.1 \pm 0.03$ & 32 & 48 \\
2 & $0.73 \pm 0.01$ & $0.72 \pm 0.01$ & $0.77 \pm 0.05$ & $0.98 \pm 0.03$ & 18 & 18 \\
\hline
\end{tabular}

fixed on the heated part of the tube, $6 \mathrm{~cm}$ after the first electrode and $6 \mathrm{~cm}$ before the second. They are calibrated with a Rosemount $162-\mathrm{CE}$ platinum resistance thermometer in the range $0-35^{\circ} \mathrm{C}$. The temperatures are then calculated with second order polynomials. In melting ice the thermocouples measure $0 \pm 0.1{ }^{\circ} \mathrm{C}$ so that the global temperature measurements accuracy is estimated at $\pm 0.1 \mathrm{~K}$.

The entrance and exit manifolds have pressure and temperature taps to measure the fluid pressure and temperature. We used an absolute pressure sensor (Rosemount type II) at the entrance calibrated from 1 to 7 bar with a \pm 25 mbar accuracy, a first differential pressure sensor (Kent-Deltapi-K) between the test section entrance and exit calibrated from 0 to 400 mbar with a \pm 1 mbar accuracy, a second differential pressure sensor (Rosemount) calibrated from 0 to 75 mbar with a \pm 0.15 mbar accuracy and two type $\mathrm{K}$ thermocouples to measure the inlet and oulet fluid temperature calibrated from 0 to $35{ }^{\circ} \mathrm{C}$ with a $0.1{ }^{\circ} \mathrm{C}$ accuracy. The three pressure sensors are calibrated with a DRUCK pressure measurement standard. The flexible tubes between the pressure taps and the pressure sensors were not heated because the working pressure was far from the saturation pressure at atmospheric temperature. The current intensity is measured by a shunt in the power supply used for joule effect heating ( $\pm 4 \mathrm{~A})$. The voltage is measured directly between the two electrodes $( \pm 1 \mathrm{mV})$. The calibrated coriolis mass flowmeter uncertainty was $\pm(0.1 \% \cdot \dot{M}+0.054)$.

\section{Operating conditions and procedure}

Table 2 shows operating conditions for the study of the friction factor and heat transfer coefficient. The mass flow rate range was chosen so that we could observe the transition from laminar to turbulent regime. The R134a thermo-physical properties were calculated with the REFPROP 6.1 software. Pressure dependence of these properties was not taken into account around the working pressure since it is not sensitive with sub-cooled liquid. For the heat transfer study the heat flux was chosen so that the fluid temperature rise should be maximal and the exit sub-cooling maintained high enough $(\approx 5 \mathrm{~K})$ to improve the accuracy. The wall temperature was kept under $T_{\text {sat }}$. After a $3 \mathrm{~h}$ long stabilisation period signals from sensors are monitored through a HP3421 data logger and averaged by groups
Table 2

Operating conditions

\begin{tabular}{lll}
\hline & Tube 1 & Tube 2 \\
\hline Friction factor & & \\
$\dot{m}\left(\mathrm{~kg} / \mathrm{m}^{2} \mathrm{~s}\right)$ & $50-600$ & $155-2800$ \\
$\Delta T_{\text {sub, }}(\mathrm{K})$ & $5-23$ & $45-65$ \\
$p_{\mathrm{e}}($ bar $)$ & $4-5$ & $15-19$ \\
Flow & Ascendant & Horizontal \\
& & \\
Heat transfer coefficient & & \\
$\dot{m}\left(\mathrm{~kg} / \mathrm{m}^{2} \mathrm{~s}\right)$ & $65-600$ & $95-2900$ \\
$\dot{q}\left(\mathrm{~W} / \mathrm{m}^{2}\right)$ & $210-2500$ & $940-49700$ \\
$\Delta T_{\text {sub, }}(\mathrm{K})$ & $7-18$ & $45-65$ \\
$p_{\mathrm{e}}($ bar $)$ & 9 & $15-19$ \\
Flow & Ascendant & Ascendant \\
\hline
\end{tabular}

Table 3

Measurements and uncertainties

\begin{tabular}{lll}
\hline & Range & Error \\
\hline$\dot{m}\left(\mathrm{~kg} / \mathrm{m}^{2} \mathrm{~s}\right)$ & $50-2800$ & $\pm 1.5-9 \%$ \\
$\dot{q}\left(\mathrm{~W} / \mathrm{m}^{2}\right)$ & $210-49700$ & $\pm 3-6 \%$ \\
$T\left({ }^{\circ} \mathrm{C}\right)$ & $0-55$ & $\pm 0.1{ }^{\circ} \mathrm{C}$ \\
$\Delta P(\mathrm{mbar})$ & $4-1700$ & $0.3-13 \%$ \\
$D_{\mathrm{h}}(\mathrm{mm})$ & 1.17 and 0.77 & $4-7 \%$ \\
$\Delta z(\mathrm{~mm})$ & 1050 and 1100 & $\pm 0.5 \%$ \\
\hline
\end{tabular}

of 20 as advised by Moffat [7]. Table 3 summarises the different measurements and their total uncertainties (taking into account statistical errors). For uncertainties calculations the Moffat [8] and Kline and Mc Klintock [9] methods were used.

\section{The friction factor}

\subsection{Results}

The total pressure loss through the test section is:

$\Delta p_{\text {exp }}=\Delta p_{\mathrm{f}}+\Delta p_{\text {sing }}+\Delta p_{\mathrm{g}}$

with

$\Delta p_{\mathrm{f}}=\frac{\dot{m}^{2}}{2 \rho_{l}} \cdot 4 f \cdot \frac{\Delta z}{D_{\mathrm{h}}}$

$\Delta p_{\mathrm{g}}=\rho_{l} \cdot g \cdot \Delta z$

$\Delta p_{\text {sing }}=\frac{\dot{m}^{2}}{2 \rho_{l}} \cdot \xi$

yielding

$4 f+\xi \cdot \frac{D_{\mathrm{h}}}{\Delta z}=\frac{2 \rho_{l} \cdot D_{\mathrm{h}}}{\dot{m}^{2} \cdot \Delta z}\left(\Delta p_{\exp }-\rho_{l} \cdot g \cdot \Delta z\right)$. 
Table 4

$4 f$ and $R e$ global uncertainties

\begin{tabular}{lll}
\hline & $\Delta R e / R e$ & $\Delta\left(4 f+\xi \cdot D_{\mathrm{h}} / \Delta z\right) /\left(4 f+\xi \cdot D_{\mathrm{h}} / \Delta z\right)$ \\
\hline Tube 1 & $\pm 10 \%$ & $\pm 15 \%$ \\
Tube 2 & $\pm 4 \%$ & $\pm 7 \%$ \\
\hline
\end{tabular}

In the vertical configuration (tube 1) the liquid height was calculated with the pressure loss without flow. Table 4 shows final uncertainties on $R e$ and $4 f$. These are mainly due to errors on the channels dimensions. The pressure losses through the straight sections of the manifolds have been neglected because of their large diameter compared to the mini-channels $(0.3 \%$ of the total pressure loss).

Figs. 3 and 4 represent the left hand term in Eq. (5) as a function of the Reynolds number. The Shah and London [10] correlation for a laminar flow in a rectangular channel,

$4 f \cdot R e=96\left(1-1.3553 \cdot \gamma+1.9467 \cdot \gamma^{2}-1.7012\right.$.

$$
\left.\gamma^{3}+0.9564 \cdot \gamma^{4}-0.2537 \cdot \gamma^{5}\right),
$$

and the Blasius correlation for a turbulent flow

$4 f=0.316 \cdot R e^{-0.25}$,

are also represented.

These results are very sensitive to the accuracy on the hydraulic diameter. Considering only geometric uncertainties yields:

$D_{\mathrm{h}}=\frac{2 \cdot l \cdot h}{l+h}$

$\frac{\Delta D_{\mathrm{h}}}{D_{\mathrm{h}}}=\frac{\Delta l}{l}+\frac{\Delta h}{h}+\frac{\Delta(l+h)}{l+h} \approx 3 \frac{\Delta l}{l}$

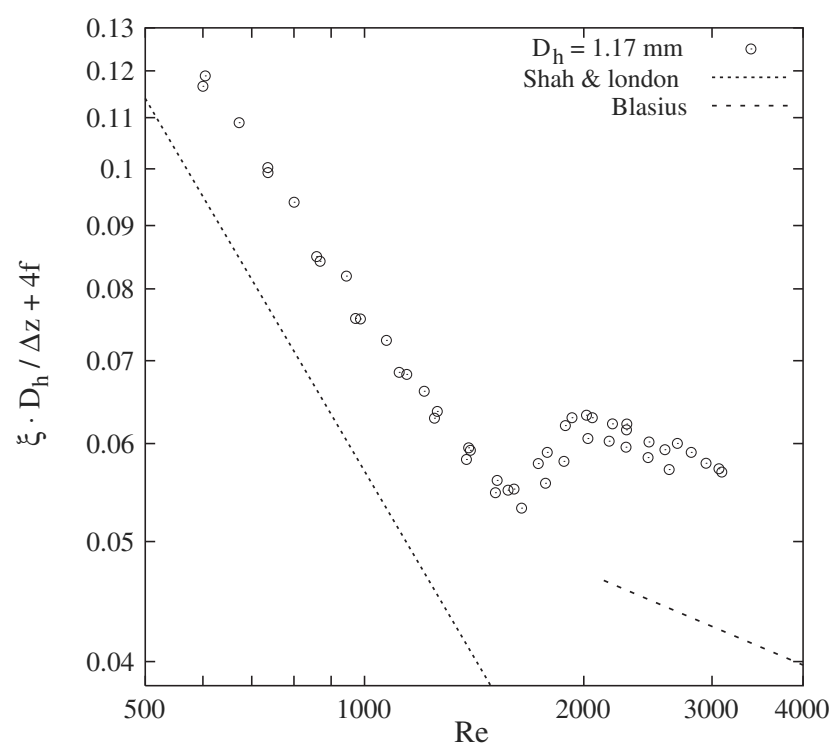

Fig. 3. $4 f+\xi \cdot D_{\mathrm{h}} / \Delta z$ versus $R e\left(D_{\mathrm{h}}=1.17 \mathrm{~mm}\right)$.

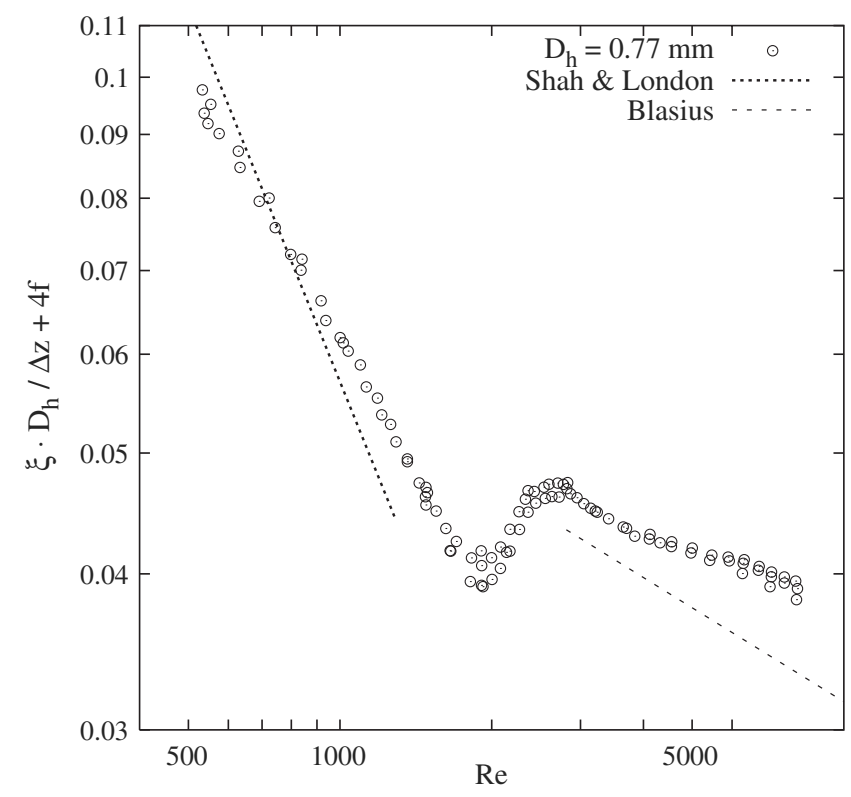

Fig. $4.4 f+\xi \cdot D_{\mathrm{h}} / \Delta z$ versus $\operatorname{Re}\left(D_{\mathrm{h}}=0.77 \mathrm{~mm}\right)$.

$4 f=\Delta p_{\mathrm{f}} \cdot \frac{D_{\mathrm{h}}}{\Delta z} \cdot \frac{2 \rho_{l}(l \cdot h)^{2} \cdot N^{2}}{\dot{M}^{2}}$

$\frac{\Delta 4 f}{4 f}=2 \frac{\Delta l}{l}+2 \frac{\Delta h}{h}+\frac{\Delta D_{\mathrm{h}}}{D_{\mathrm{h}}} \approx 7 \frac{\Delta l}{l}$.

Thus a $3 \%$ uncertainty on $l$ and $h$ generates a $21 \%$ uncertainty on $4 f$ in the laminar regime.

\subsection{Analysis}

Our measurements on tube 2 show that classical literature results on friction factors in large tubes are still usable in mini-channels. However tube 1 measurements demonstrate that singular pressure losses were not negligible as for tube 2. These are difficult to evaluate because of high manifold to channel flow area ratios which were not found in literature. Furthermore, the laminar and turbulent regimes clearly appear and the transition occurs for $1800<R e<2000$. An uncertainties weighted linear regression was performed on the friction factor and leaded to results gathered in Table 5. These data show that the singular pressure loss coefficient for tube 1 can be estimated at $\xi \approx 20$.

\section{The heat transfer coefficient}

\subsection{Data reduction}

A power balance applied on our data showed that a correction taking into account heat transfer with the surroundings was necessary to obtain power losses below $10 \%$ for all data and $5 \%$ for most of them in the case 
Table 5

Comparison of friction results with literature

\begin{tabular}{lllll}
\hline Tube & $\left(4 f+\xi \cdot\left(D_{\mathrm{h}} / \Delta z\right)\right) \times R e, R e<1800$ & $\left(4 f+\xi \cdot\left(D_{\mathrm{h}} / \Delta z\right)\right) \times R e^{0.25}, R e>2000$ & Shah and London & Blasius \\
\hline 1 & $(58 \pm 12)+(22 \pm 2) \cdot R e$ & $(0.419 \pm 0.02)+(18 \pm 1) \cdot R e^{0.25}$ & 57 & 0.316 \\
2 & $57 \pm 11$ & $0.347 \pm 0.004$ & 57 & 0.316 \\
\hline
\end{tabular}

of tube 1 . Thus the wall heat flux for tube 1 measurements was calculated by

$\dot{q}(z)=\frac{U \cdot I}{S}-\alpha_{\mathrm{atm}}\left(T_{\mathrm{w}}(z)-T_{\mathrm{atm}}\right)$,

$\alpha_{\text {atm }}$ being a global heat transfer coefficient taking into account natural convection, radiation, and insulator thickness. It is estimated with the power balance which leads to coherent values. For tube $2 \alpha_{\text {atm }}$ is negligible because with a higher working pressure we achieved heat fluxes high enough to reduce the uncertainty.

The thermocouples are fixed on the external tube surface while the internal wall temperature is needed to calculate the heat transfer coefficient at wall/R134a interface. We solved the heat equation to estimate the difference between these two temperatures, finally yielding $\Delta T \approx 0.01 \mathrm{~K}$. Since the temperature difference is less than the uncertainty on temperature measurements, the measured wall temperature is taken as the internal wall temperature. We used the corrected heat flux of Eq. (12) to calculate the fluid temperature yielding:

$T_{\mathrm{fl}}(z)=T_{\mathrm{fl}, \mathrm{i}}+\int_{0}^{z} \frac{\dot{q}(z) \cdot S}{\dot{M} \cdot c_{p}(z) \cdot L} \mathrm{~d} z$.

\subsection{Results}

The global Nusselt number is calculated as follows:

$$
\begin{gathered}
N u_{\mathrm{G}}=\frac{\alpha_{\mathrm{G}} \cdot D_{\mathrm{h}}}{\overline{\lambda_{\mathrm{fl}}}}, \quad \alpha_{\mathrm{G}}=\frac{\overline{\dot{q}}}{\Delta T_{\mathrm{lm}}}, \\
\overline{\lambda_{\mathrm{fl}}}=\frac{\lambda_{\mathrm{fl}}(0)+\lambda_{\mathrm{fl}}(L)}{2} .
\end{gathered}
$$

$\Delta T_{\mathrm{lm}}$ being defined as

$$
\Delta T_{\mathrm{lm}}=\frac{\left(T_{\mathrm{w}, 0}-T_{\mathrm{fl}, 0}\right)-\left(T_{\mathrm{w}, 1}-T_{\mathrm{fl}, 1}\right)}{\ln \left(\frac{T_{\mathrm{w}, 0}-T_{\mathrm{fl}, 0}}{T_{\mathrm{w}, 1}-T_{\mathrm{ffl}, 1}}\right)}
$$

The laminar-turbulent transition occurs for $1800<$ $R e<2000$ as with the friction factor but the transition is smoother for tube 2. As shown on Fig. 5 the uncertainty on $T_{\mathrm{w}}$ is multiplied by 3 in the transition region certainly because of flow instabilities. Figs. 6 and 7 show the global Nusselt number compared to literature correlations for large tubes. In the turbulent regime our data are well predicted by the Gnielinsky correlation:

$N u=\frac{(f / 2) \cdot(\operatorname{Re}-1000) \cdot \operatorname{Pr}}{1+12.7 \sqrt{f / 2}\left(\operatorname{Pr}^{2 / 3}-1\right)}$

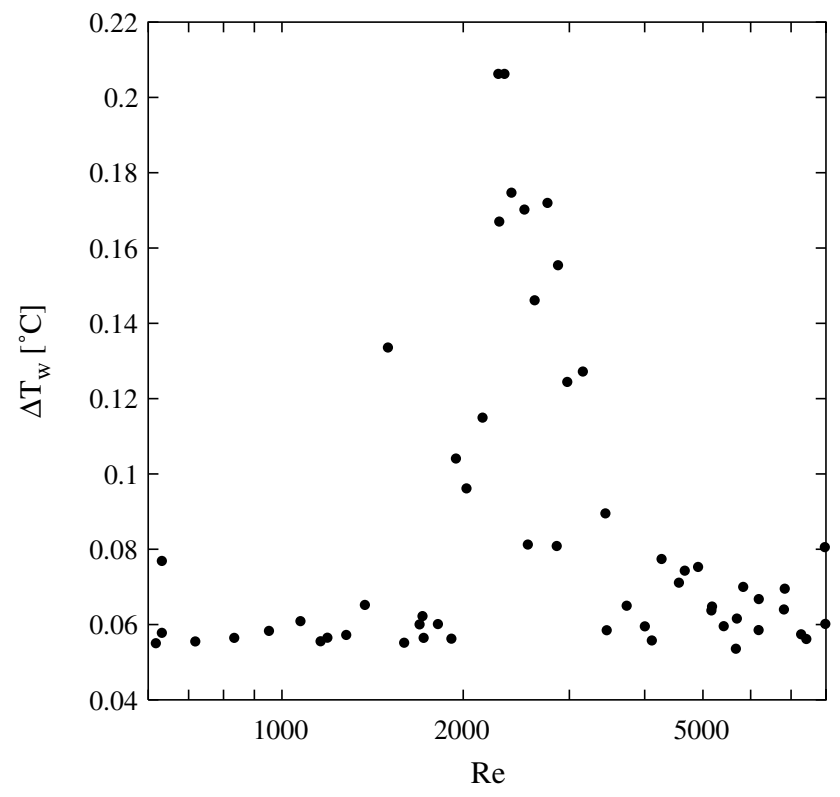

Fig. 5. Total uncertainity on $T_{\mathrm{w}}\left(D_{\mathrm{h}}=0.77 \mathrm{~mm}\right)$.

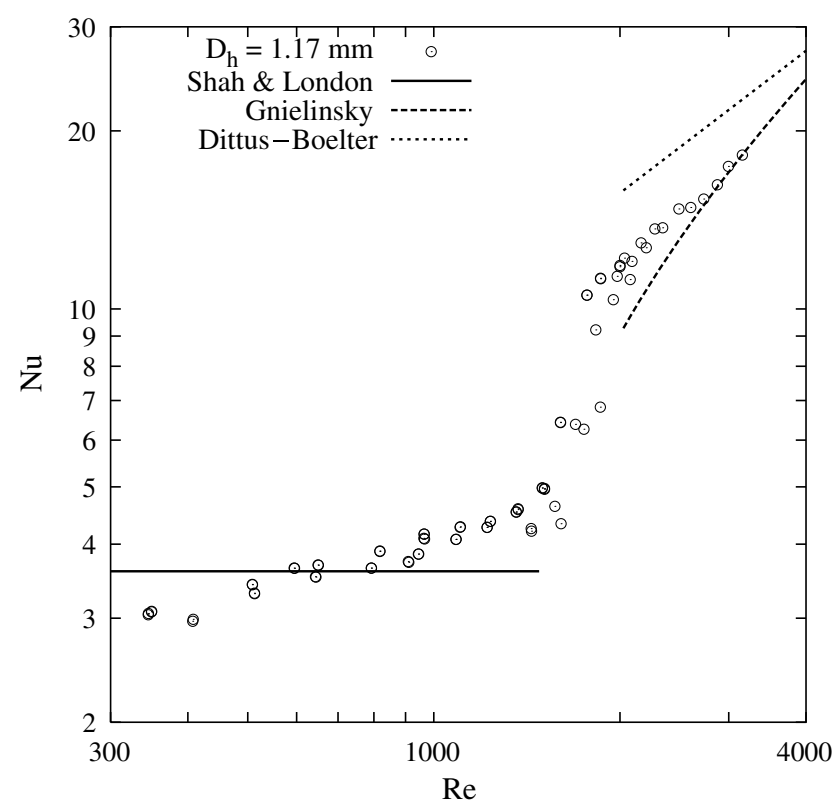

Fig. 6. Global Nusselt number $\left(D_{\mathrm{h}}=1.17 \mathrm{~mm}\right)$.

$4 f=(1.82 \cdot \log (R e)-1.64)^{-2}$,

with $2300<\operatorname{Re}<10^{6}, 0.6<\operatorname{Pr}<10^{5}$. The DittusBoelter correlation is also represented for comparison. 


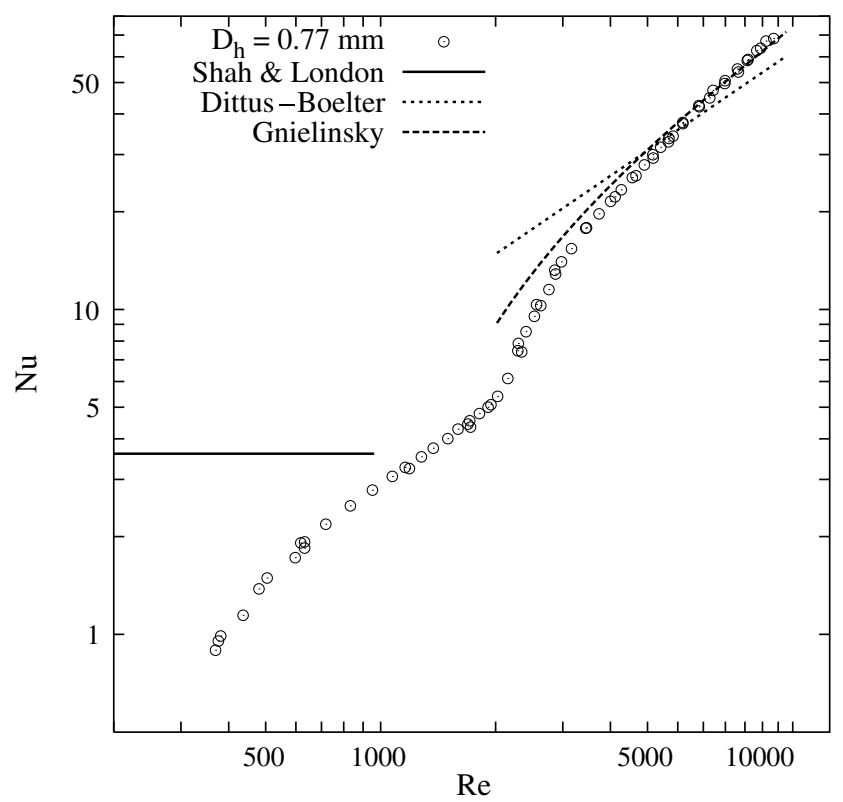

Fig. 7. Global Nusselt number $\left(D_{\mathrm{h}}=0.77 \mathrm{~mm}\right)$.

The Shah and London [10] correlation for uniform heat flux heating,

$$
\begin{aligned}
N u= & 8.235\left(1-2.0421 \cdot \gamma+3.0853 \cdot \gamma^{2}-2.4753 \cdot \gamma^{3}\right. \\
& \left.+1.0578 \cdot \gamma^{4}-0.1861 \cdot \gamma^{5}\right),
\end{aligned}
$$

is within experimental errors for tube 1 but over predicts them for tube 2 when $R e<1000$. Further investigations with a varying heat flux for a fixed mass flux are in progress to check this phenomenon. The thermal entry length may be calculated by $L_{\mathrm{th}} / D_{\mathrm{h}}=0.0431 \cdot R e \cdot P r$ [11] supposing it is still valid for mini-channels. Table 6 shows that for tube $1 \mathrm{up}$ to half the tube length is in the thermal entry length and up to four for tube 2. This could explain a slight increase of $N u$ with $R e$ in the laminar regime, but not as much as observed for tube 2 .

The fluid temperature increase is less than $10{ }^{\circ} \mathrm{C}$ along the test section for tube 1 so that the Reynolds and Prandtl numbers variation along the test section is small, on the contrary the temperature increase can reach $50{ }^{\circ} \mathrm{C}$ for tube 2 and the variations along the test section are:

$\pm 2.5 \%<\frac{\Delta R e}{R e}< \pm 21 \%$ and $\pm 1.3 \%<\frac{\Delta P r}{\operatorname{Pr}}< \pm 9 \%$.

However the Prandtl number variation with fluid temperature is within error bars. Furthermore the dynamic

Table 6

Thermal entry lengths

\begin{tabular}{llll}
\hline & $L / D_{\mathrm{h}}$ & $L_{\mathrm{th}} / D_{\mathrm{h}}$ & \\
\cline { 3 - 4 } & & $R e=300$ & $R e=1500$ \\
\hline Tube 1 & 610 & 50 & 246 \\
Tube 2 & 903 & 50 & 246 \\
\hline
\end{tabular}

viscosity variation from the tube wall to the bulk flow is negligible: $\mu_{\mathrm{w}} / \mu_{\mathrm{bulk}}<1.05$. Table 7 shows the global uncertainties on $\mathrm{Nu}$ and $\mathrm{Re}$.

Table 7

$\mathrm{Nu}$ and $\mathrm{Re}$ uncertainties

\begin{tabular}{lll}
\hline & $\Delta R e / R e$ & $\Delta N u / N u$ \\
\hline Tube 1 & $\pm 4.7 \%$ & $\pm 7-28 \%$ \\
Tube 2 & $\pm 7.8 \%$ & $\pm 8.5-11 \%$ \\
\hline
\end{tabular}

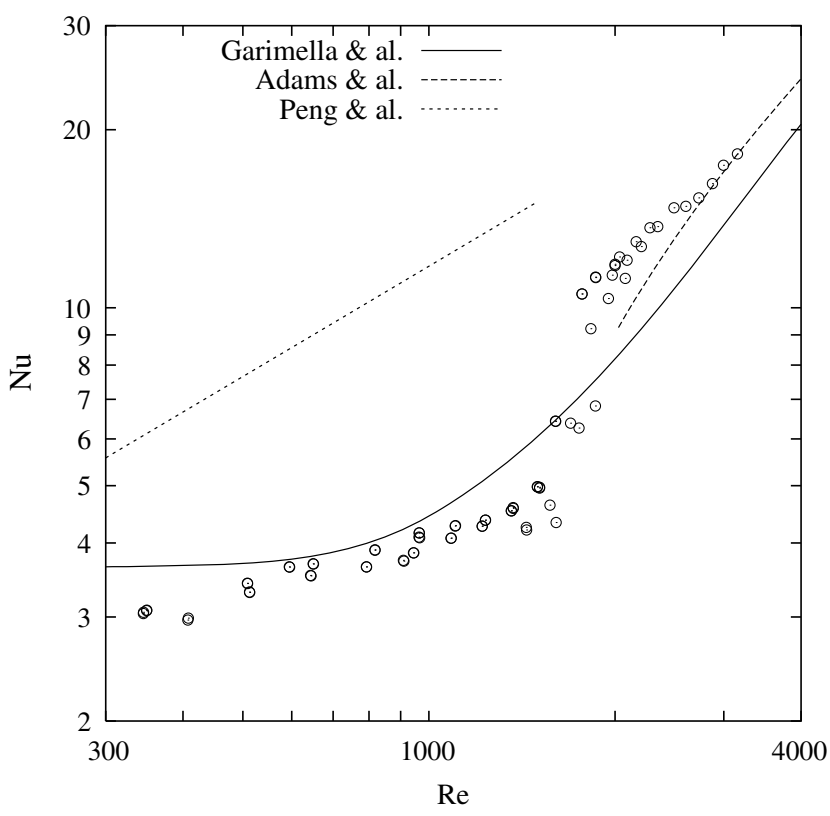

Fig. 8. Comparison with mini-channel correlations $\left(D_{\mathrm{h}}=1.17 \mathrm{~mm}\right)$.

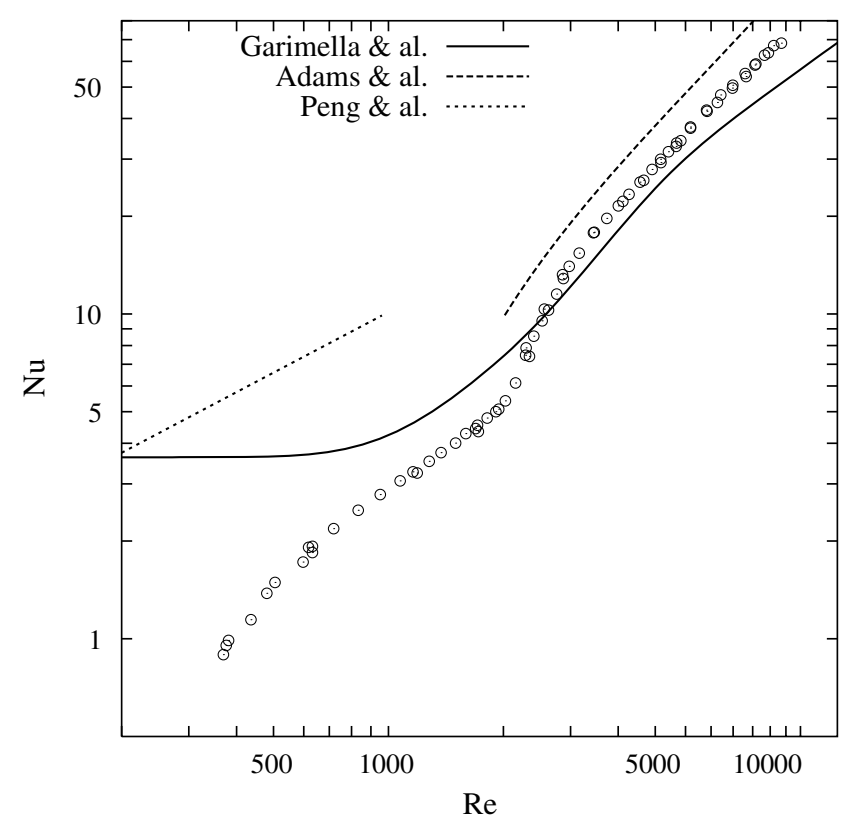

Fig. 9. Comparison with mini-channel correlations $\left(D_{\mathrm{h}}=0.77 \mathrm{~mm}\right)$. 


\subsection{Comparison with mini-channels correlations}

Figs. 8 and 9 show the correlations established by Peng and Peterson [1], Adams et al. [2] and Garimella et al. [3] in mini-channels compared to our data. The Peng et al. correlation over predicts our data but was devised for $D_{\mathrm{h}}<0.75 \mathrm{~mm}$ and shorter channels with a higher $L / D_{\mathrm{h}}$. The Adams et al. correlation in the turbulent regime seems not more reliable than the Gnielinsky correlation. The best results are obtained with the Garimella et al. correlation although operating conditions are slightly different, especially for the aspect ratio.

\section{Conclusions}

This experimental campaign convinced us that the study of mini-channels should put the emphasis on uncertainties. Small uncertainties on the channels dimensions imply high errors on the friction factor so that dimensions should be known better than $\pm 1 \%$. For heat transfer studies the thermal insulation was a major concern and power balances better than $10 \%$ were obtained with temperatures corrections for heat transfer with the surroundings for tube 1 , that is why we used a far higher working pressure for tube 2 to achieve higher heat fluxes. In the data reduction process both the heat flux and local fluid temperature are affected by uncertainties on the power dissipated in the test section so that the Nusselt number in the laminar regime is quite sensitive to the power balance.

The laminar-turbulent transition occurs around $R e=2000$ as expected for both friction factor and heat exchange coefficient measurements. Friction factors were found to be correctly predicted with classical relations for tube 2 but were slightly under estimated for tube 1 because of singular pressure losses. We showed that the Gnielinsky correlation is still convenient in mini-channels when $R e>2000$ and the Garimella et al.
[3] correlation best predicts our data among minichannels correlations. In the laminar regime, the Shah and London [10] law was able to predict our measurements in tube 1 but failed with tube 2, especially for lowest Reynolds numbers. However a longitudinal conductive heat flux in aluminium as low as $0.2 \mathrm{~W}$ can explain this result so that we are currently working on this explanation. Further investigations on boiling heat transfer in such channels are in progress on both tubes.

\section{References}

[1] X. Peng, G. Peterson, Convective heat transfer and flow friction for water flow in microchannels structures, International Journal of Heat and Mass Transfer 39 (12) (1996) 2599-2608.

[2] T. Adams, S. Abdel-Khalik, S. Jeter, Z. Qureshi, An experimental investigation of single-phase forced convection in microchannels, International Journal of Heat and Mass Transfer 41 (6-7) (1998) 851-857.

[3] S. Garimella, W. Dowling, M.V.D. Veen, J. Killion, The effect of simultaneously developing flow on heat transfer in rectangular tubes, Heat Transfer Engineering 22 (6) (2001) 12-25.

[4] J. Chen, Correlation for boiling heat transfer to saturated fluids in convective flow, Industrial Engineering and Chemistry Process Design and Development 5 (3) (1966) 322-329.

[5] M. Shah, A new correlation for heat transfer during boiling flow through pipes, Transactions of the ASHRAE 82 (1976) 6686

[6] Z. Liu, R. Winterton, A general correlation for saturated and subcooled flow boiling in tubes and annuli, based on a nucleate pool boiling equation, International Journal of Heat and Mass Transfer 34 (11) (1991) 2759-2766.

[7] R. Moffat, Contributions to the theory of single-sample uncertainty analysis, Journal of Fluids Engineering 104 (1982) 250-261.

[8] R. Moffat, Using uncertainty analysis in the planning of an experiment, Journal of Fluids Engineering 107 (1985) 173-182.

[9] S. Kline, F. McClintock, Describing uncertainties in single-sample experiments, Mechanical Engineering (1953) 3-8.

[10] R. Shah, A. London, Laminar Flow Forced Convection in Ducts, Academic Press, 1978.

[11] J. Taine, J.-P. Petit, Transferts thermiques, Dunod Université, 1989. 